\title{
2
}

\section{Theorizing Modernity and Technology}

Philip Brey

The Need for Integrated Studies of Modernity and Technology

Technology made modernity possible. It has been the engine of modernity, shaping it and propelling it forward. The Renaissance was made possible by major fourteenth- and fifteenth-century inventions like the mechanical clock, the full-rigged ship, fixed-viewpoint perspective, global maps, and the printing press. The emergence of industrial society in the eighteenth century was the result of an industrial revolution that was made possible by technological innovations in metallurgy, chemical technology, and mechanical engineering. The recent emergence of an information society is also the product of a largely technological revolution, in information technology. Technology has catalyzed the transition to modernity and catalyzed major transitions within it. More than that, technologies are and continue to be an integral part of the infrastructure of modernity, being deeply implicated in its institutions, organizing and reorganizing the industrial system of production, the capitalist economic system, surveillance and military power; and shaping cultural symbols, categories, and practices (see Lyon and Edwards, chapters 6 and 7 in this volume).

If modernity is shaped by technology, then the converse also holds: technology is a creation of modernity. The common wisdom of technology studies, that technology is socially shaped or even socially constructed, that it is "society made durable," implies that a full understanding of modern technology and its evolution requires a conception of modernity within which modern technology can be explained as one of its products. If this holds for technology at large, it certainly 
also holds for particular technologies, technical artifacts, and systems. These are also products of modernity and bear the imprint, not only of the behaviors of actors immediately involved in their construction, but also of the larger sociocultural and economic conditions within which they are developed. To ignore this larger context is to leave out part of the story that can be told about that technology. It would be like staging Wagner's Parsifal with only the actors on stage, without any settings, costumes, or props.

In the current specialized academic landscape, modernity is the object of study of modernity theory, and technology is studied in technology studies. Few works exist that bridge these two fields and that study technology with extensive reference to modernity, or modernity with extensive reference to technology, or that concentrate on both by studying the way in which evolutions within modernity intersect with technological changes. In modernity theory, technology is often treated as a "black box" that is discussed, if at all, in abstract and often essentialist and technological determinist terms. In technology studies, the black box of technology is opened, and technologies and their development are studied in great empirical detail, yet technology studies generate their own black box, which is society. The larger sociocultural and economic context in which actors operate is either treated as a background phenomenon to which some hand-waving references are made, or it is not treated at all-a black box returned to sender, address unknown.

Undoubtedly, part of the reason that modernity theory has not adequately come to grips with technology has been the lack of empirically informed accounts of technology. It is only in the past few decades that major progress has been made in our understanding of technology and technological change, with the establishment of technology studies as a mature field of study. The same reason cannot be given for the lack of reference to modernity theory in technology studies because modernity theory has been around a lot longer than technology studies. Here, this lack of reference is more likely explained by the abstract and totalizing character of many theories of modernity; their often inadequate accounts of technology; the speculative, untested character of many of their claims; and the difficulty of connecting the microlevel concepts of technology studies to the macrolevel categories of modernity theory. 
These criticisms do not apply equally to all theories of modernity. There is a world of difference between the abstract, totalizing theories of modernity of classical critical theory, Marxism, and phenomenology, and many recent theories of modernity, such as those of David Harvey and Manuel Castells, that are empirically rich and mindful of heterogeneity and difference. So if the sociocultural and economic context that is modernity ought to be considered in technology studies, then technology studies should work to appropriate more adequate theories of modernity, or start developing its own. ${ }^{1}$

It is time, then, to bridge the disciplinary gaps that now separate modernity theory and technology studies and to work at empirically informed and theoretically sophisticated accounts of technology, modernity, and their mutual shaping. In this essay, I contribute to this task through an analysis of the problems and misunderstanding that now beset modernity theory and technology studies in their respective treatment (or nontreatment) of technology and modernity.

A key conclusion is that the major obstacle to a future synthesis of modernity theory and technology studies is that technology studies mostly operate at the micro (and meso) level, whereas modernity theory operates at the macrolevel, and it is difficult to link the two. I analyze the micro-macro problem and ways in which it may be overcome in technology studies and modernity theory. The next two sections provide basic expositions of concepts, themes, and approaches in modernity theory and technology studies. Their aim is to introduce these fields to readers insufficiently familiar with them, as well as to set the stage for the analysis that follows.

\section{Modernity Theory: Understanding the Modern Condition}

\section{Structure and Aims}

Modernity is the historical condition that characterizes modern societies, cultures, and human agents. Theories of modernity aim to describe and analyze this historical condition. A distinction can be made between cultural and epistemological theories of modernity, most of which are found in the humanities, and institutional theories, which are common in social theory-although in both traditions many theories of modernity 
can be found that blend cultural, institutional, and epistemological aspects.

Cultural and epistemological theories of modernity focus on the distinction between premodern and modern cultural forms and modes of knowledge. These theories usually place the transition from traditional society to modernity in the Renaissance period, in fifteenth- and sixteenth-century Europe. The transition to modernity, in this conception, is characterized by the emergence of the notion of an autonomous subject, the transition from an organic to a mechanistic world picture, and the embrace of humanistic values and objective scientific inquiry. Some theories date the transition to modernity later than this, as late as the eighteenth century, during which Enlightenment thought had culminated in a genuine project of modernity, with universal pretensions to progress, and with fully developed conceptions of objective science, universal morality and law, and autonomous art (e.g., Habermas 1983). The cultural-epistemological approach to modernity dominates in philosophy, with Hegel, Nietzsche, and Heidegger as early proponents, and is also well represented in cultural history and cultural studies.

Many studies in the humanities that analyze modernity as a cultural phenomenon also focus on modernism, which is a phenomenon distinct from modernity. Modernism, or aesthetic modernism, as it is also called, was a cultural movement that began in the mid-nineteenth century as a reaction against the European realist tradition, in which works of art were intended to "mirror" external nature or society, without any additions or subtractions by the artist. Modernist artists, in often quite different ways, rejected this realism and held that it is the form of works of art, rather than their content, that guarantees authenticity and liberates art from tradition. Modernism has been very influential in literature, in the visual arts, and in architecture, with movements as diverse as naturalism, expressionism, surrealism, and functionalism being collected under it.

The emergence of modernism has often been explained by reference to major social transformations in nineteenth- and early twentieth-century modernity. David Harvey, for instance, has argued that modernism was a cultural response to a crisis in the experience of space and time, which was the result of processes of time-space compression under late 
nineteenth-century capitalism (Harvey 1989, chap. 8). The label "modernism" is also used in a broader sense, in which it does not refer to an aesthetic movement, but to the culture and ideology of modernity at large (e.g., Bell 1976). "Modernism," in this sense, stands for positivism, rationalism, the belief in linear progress and universal truth, the rational planning of ideal social orders, and the standardization of knowledge and production. When used in this latter sense, the notion of modernism becomes almost interchangeable with the notion of modernity construed as a cultural or epistemological condition (see Berman 1982).

Institutional theories of modernity focus on the social and institutional structure of modern societies, and tend to locate the transition to modernity in the eighteenth century, with the rise of industrial society in Europe. Institutional theories of modernity are as old as social theory itself, with early proponents like Weber, Marx, and Durkheim outlining key structural features of modern societies and theorizing major transitions from traditional to modern society. Modernity, in the institutional conception, is a mode of social life or organization rather than a cultural or epistemological condition. It is characterized by institutional structures and processes, such as industrialism, capitalism, rationalization, and reflexivity. It is with this institutional meaning of modernity that one can correlate the notion of modernization, which is the transformation of traditional societies into industrial societies. Modernity used to describe a condition that emerged in eighteenth-century European societies, but today it characterizes industrial societies around the globe. ${ }^{2}$

In my discussion of modernity theory, I give special emphasis to the social theory tradition, with the understanding that much of this work analyzes not only institutional aspects of modernity but cultural and epistemological dimensions as well. Indeed, it is quite common to see these aspects combined in social theories of modernity, even if institutional features receive the most emphasis. This blending of traditions has been particularly strong in critical theory, with authors like Habermas, Marcuse, and Adorno referring to Hegel and Heidegger as liberally as to Marx and Weber. However, it is also quite visible in more recent theories of modernity, such as those of Giddens, Harvey, Wagner, and Castells, as well as in the early institutional theories of modernity developed by Weber and Marx. 
Theories of modernity in the social theory tradition present an account of the distinct structural features that characterize modern societies and the way these features came into being. Typically, they contain most or all of the following elements:

- They draw the boundaries of modernity as a historical period, contrasting it with a premodern period and sometimes also with a postmodern period.

- They describe and analyze the special features of modernity, with an emphasis on institutional, cultural, or epistemological dimensions. They almost invariably do this through macrolevel or "abstract" analysis. However, they may contain various elaborations, case studies, or illustrations of the macro theory.

- They (optionally) describe the dynamics of modernity, delineating (1) the historic changes that led to modern society, (2) various epochs within modernity (e.g., early, high, and late modernity; classical and reflexive modernity), and (3) the transitions between these epochs.

- Some theories of modernity also contain normative evaluations or critiques of the condition of modernity. Some propose visions of an alternative society or speculate how present modernity may transform itself into another type of social formation.

Next to grand theories of modernity, such as those of Marx, Weber, Habermas, and Giddens, one can find studies of particular eras within modernity, of major transitions and developments within the modern era, and of particular features or structures of modernity. Theories of particular eras within modernity attempt to characterize a particular historical epoch and to analyze the transitions that led to it (Wagner 1994). Many contemporary social theorists focus on late modernity as a historical epoch emerging in the second half of the twentieth century, and attempt to characterize its special features. Thus, one finds theories of "reflexive modernity" (Beck et al. 1994), "the risk society" (Beck 1992), "postindustrial society" (Bell 1976; Touraine 1971), "the information age" and "the information society” (Castells 1996; Schiller 1981), “the global age” (Albrow 1996), and many others. Akin to these theories, one finds theories of postmodernity, which hypothesize that we have already left (late) modernity and have recently entered a new postmodern era (e.g., Jameson 1991; Harvey 1989). 
Besides theories of particular eras in modernity, there are many studies of major sociocultural, technological, or economic transitions within modernity. These range from studies of the scientific revolution and the industrial revolution to studies of the control revolution (a revolution in technologies of control that is claimed by Beniger [1989] to have paved the way for the information society) or the emergence of Fordism, to theories of the historical development of the modern subject and of new modern forms of power (e.g., Foucault 1977). Not all these works explicitly situate the developments they analyze within the wider context of modern social institutions and culture. Finally, one can find studies that are concerned with particular aspects or structures of modernity, such as modern identity (Lash and Friedman 1993; Giddens 1991), capitalism (Sayer 1991), pornography (Hunt 1993), consumer culture (Slater 1997), and gender (McGaw 1989; Marshall 1994; Felski 1995).

Not every work in social theory is a work in modernity theory. For it to qualify as such, it would have to be centrally concerned with major institutional, cultural, or epistemological aspects of or transformations within modernity, such as capitalism, the autonomous self, modern technology, and the Enlightenment. Alternatively, for phenomena that are not inherently tied to modernity or at least do not define it, such as pornography, adolescence, or the automobile, it would study these in relation to the larger institutional, cultural, and epistemological context of modernity. Thus, an analysis of adolescence would be a study in modernity theory if it explicitly considered the historical, cultural, and institutional constructions of adolescence in the modern era and changes in these constructions over time, but not if it treated adolescence in a largely ahistorical way (e.g., as a set of locally enacted constructions with little historical continuity), or if it studied its historical treatment in a particular country or setting without reference to its relation to modern social institutions and culture. ${ }^{3}$

\section{Modernity and Social Theory}

Theories of modernity have always held a prominent position in social theory. What follows is a brief review. Any such review will have to start with Karl Marx and Max Weber, who are often identified as the 
fathers of modernity theory. They are both known for their theories of the transition between feudal and industrial society, and their theories of (capitalist) industrial society. They are hence early proponents of institutional theories of modernity and of the transition of the premodern to the modern period.

In Marx's historical materialist conception of modernity, the difference between the modern and the premodern era is characterized by qualitative differences in the economic structure. The economic structure of a society is made up of production relations and it changes when the development of the productive forces (means of production and labor power) results in greater productive power. According to Marx, the transition from feudal to capitalist society was caused by large increases in productive power in feudal society. These increases caused changes in production relations, and hence in the economic structure. The resulting economic structure was capitalist in the late nineteenth century, but Marx of course envisioned a transition to a post-class socialist society, a transition that would occur when further increases in production power made a socialist state possible. He hence envisioned an early, capitalist, and a late, socialist state of modernity. Both are characterized by an industrial system of production, but their social form and culture are significantly different.

Weber (1958[1905]) did not see the transition from feudal to industrial society as caused by the development of productive power. Instead, he held that the capitalist economic system that made industrial society possible was an outgrowth of the Protestant work ethic, which demanded hard work and the accumulation of wealth. Because capitalism is profit based, it demanded rationalization so that results could be calculated and so that efficiency and effectiveness could be increased. In this way, rationalization became the distinguishing characteristic of modern industrial societies. The rationalization of society is the widespread acceptance of rules, efficiency, and practical results as the right way to approach human affairs and the construction of a social organization around this notion. According to Weber, rationalization has a dual face. On the one hand, it has enabled the liberation of humanity from traditional constraints and has led to increased reason and freedom. On the other hand, it has also produced a new oppression, the 
"iron cage" of modern bureaucratic organizational forms that limit human potential. ${ }^{4}$

Weber's notion of rationalization as the hallmark of modernity has been very influential in modernity theory. It has been particularly influential in critical theory, particularly with members of the Frankfurt school such as Adorno, Horkheimer, Marcuse, and Habermas, who built on Weberian notions as well as Marxist ideas in formulating their sweeping critiques of modern society (see, e.g., Marcuse 1964 and Horkheimer and Adorno 1972). Jürgen Habermas, without doubt the most influential scholar in the critical theory tradition, has advanced a theory of modernity with strong Weberian and Marxist influences, in which he analyzes modernity as an "unfinished project" (Habermas 1983). He theorizes an early phase of modernity and a later phase. Early modernity witnessed the rise of the "bourgeois public sphere," which mediated between the state and the public sphere. In late modernity, the state and private corporations took over vital functions of the public sphere, as a result of which the public sphere became a sphere of domination (Habermas 1989).

Although he is critical of late modernity, Habermas sees an emancipatory potential in early modernity, with its still-intact bourgeois public sphere. He hence sees modernity as an "unfinished project" and has attempted to redeem some elements of modernity (the Enlightenment ideal of a rational society, the modern differentiation of cultural spheres with autonomous criteria of value, the ideal of democracy) while criticizing others (the dominant role of scientific-technological rationality, the culture of experts and specialists). Central in this undertaking has been his distinction between two types of rationality: purposive or instrumental rationality, which is a means for exchange and control and which is based on a subject-object relationship, and communicative or social rationality, which is geared toward understanding and is based on a subject-subject relationship that is the basis for communicative action. Habermas claims that there has been a one-sided emphasis since the Enlightenment on instrumental, scientific-technological rationality, which has stifled possibilities for expression. The result has been a colonization of the lifeworld by an amalgamated system of economy and state, technology and science, that carries out its functional laws in all spheres of 
life. Habermas regards communicative action as a means to put boundaries on this system and to develop the lifeworld as a sphere of enlightened social integration and cultural expression.

Looking beyond critical theory, one cannot escape the powerful analysis of modernity in the work of Anthony Giddens (1990, 1991, 1994b). Giddens analyzes modernity as resting on four major institutions: industrialism, capitalism, surveillance, and military power. These and other institutions in modernity moreover exhibit an extreme dynamism and globalizing scope. To account for this dynamism, Giddens identifies three developments. The first is the separation of time and space, through new time- and space-organizing devices and techniques, from each other and from the contextual features of local places to which they were tied. Time and space become separate, empty parameters that can be used as structuring principles for large-scale social and technical systems. The second development is the disembedding of social life, the removal of social relations and institutions from local contexts by disembedding mechanisms, such as money, timetables, organization charts, and systems of expert knowledge. Disembedding mechanisms define social relations and guide social interactions without reference to the peculiarities of place. The third development is the reflexive appropriation of knowledge, which is the production of systematic knowledge about social life that is then reflexively applied to social activity. Jointly, these developments create a social dynamic of displacement, impersonality, and risk. These can be overcome through reembedding (the manufacture of familiarity), trust (in the reliability of disembedding mechanisms), and intimacy (the establishment of relationships of trust with others based on mutual processes of self-disclosure).

Risk, trust, and the reflexive appropriation of knowledge are also central themes in Ulrich Beck's theory of (late) modernity (Beck 1992). Beck distinguishes two stages of modernization, the first of which is simple modernization: the transformation of agrarian society into industrial society. The second stage, which began in the second half of the twentieth century, is that of reflexive modernization. This is a process in which modern society confronts itself with the negative consequences of (simple) modernization and moves from a conflict structure based on the distribution of goods to a model based on the distribution of risks. Our 
current society is the risk society, in which risks are manufactured by institutions and can be distributed in different ways. The distribution of risk occurs with major social transformations at the backdrop, transformations in which traditional social forms such as family and gender roles, which continued to play an important role in industrial society, are in the risk society undergoing radical change, leading to a progressive "individualization of inequality."

The idea that modernity has recently entered a new phase is pervasive in contemporary social theory, even among those authors that stop short of claiming that we have entered or are entering a phase of postmodernity. Intensifying globalization, the expansion and intensification of social reflexivity, the proliferation of nontraditional social forms, the fragmentation of authority, the fusion of political power and expertise, the transition to a post-Fordist economy that is no longer focused on mass production and consumption and in which the production of signs and spaces becomes paramount-all have been mentioned as recent developments that point to a new stage of reflexive or radicalized modernity (e.g., Lash and Urry 1994; Beck et al. 1994; Giddens 1990, 1994b; Albrow 1996; Lipietz 1987), with most authors identifying the late 1970 s as a transition period. Many authors point specifically to the revolution in information technology in claiming that we have entered an information age (or, equivalently, a postindustrial age) in which an economy based on information, not goods, has become the organizing principle of society (e.g., Bell 1976; see Webster 1995 for an overview).

In the transition from an industrial to an information society, the economic system is transformed, and along with it the occupational structure, the structure of organizations, and social structure and culture at large. According to Manuel Castells, who has presented the most comprehensive theory of the information society to date, the basic unit of economic organization in the information age is the network, made up of subjects and organizations, and continually modified as networks adapt to their (market) environments. Castells argues that contemporary society is characterized by a bipolar opposition between the Net (the abstract universalism of global networks) and the Self (the strategies by which people try to affirm their identities), which is the source of new forms of social struggle (Castells 1996, 1997, 1998). 


\section{Modernity and Postmodernity}

Not all scholars agree that modernity is still the condition that we are in. Theorists of postmodernity claim that we have recently entered an era of postmodernity, which follows modernity. Postmodernity is often considered, like modernity, to be a historical condition. Most theorists who consider postmodernity in this way place the transition from modern to postmodern society somewhere in the 1960 s or 1970 s, although some hold that we are still in the middle of a transition phase. They hold that changes in society over the past century accumulated during these decades to produce a society whose institutional, cultural, or epistemological condition is sufficiently different from that of modern society to warrant the new label.

Many postmodern theorists point only to cultural changes to support this claim. Some, however, emphasize technological and economic changes and see changes in cultural and social forms as resulting from them. David Harvey emphasizes the 1970s transition from a Fordist economy of mass production and consumption to a global post-Fordist regime characterized by greater product differentiation, intensified rates of technological and organizational innovation, and more flexible use of labor power (Harvey 1989). Frederick Jameson has theorized a transition to "late capitalism," which is global and in which all realms of personal and social life and spheres of knowledge are turned into commodities. He claims that late capitalism comes with its own cultural logic, which is postmodernism (Jameson 1991). Lash and Urry (1994) point to the shift from an economy of goods to an economy of signs and spaces, as does Jean Baudrillard (1995), who claims that information technology, mass media, and cybernetics have effected a transition from an era of industrial production to an era of simulation, in which models, signs, and codes determine new social orders. The culture of postmodernity is often characterized by consumerism, commodification, the simulation of knowledge and experience; the blurring if not disappearance of the distinction between representation and reality; and an orientation on the present that erases both past history and a sense of a significantly different future. The cultural shifts also include a decline in epistemic and political authority, the fragmentation of experience and personal identity, and the emergence of a disorienting postmodern hyperspace. 
Not all postmodern theorists hold postmodernity to be a historical condition, however. For some, like Jean-François Lyotard, postmodernity is rather a cultural or epistemological form that is not essentially tied to a particular historical period. Lyotard holds that within contemporary society, one can find both modern and postmodern forms existing together. ${ }^{5}$ The characteristic of postmoderns like Lyotard is that they resist the modern form. For Lyotard, modernity is equivalent to reason, the Enlightenment, totalizing and universalizing thought, and grand historical narratives. It is equivalent to what I identified earlier as modernism in a broad sense, that is, the culture and ideology of modernity. Lyotard criticizes the modern form of knowledge and calls for new kinds of knowledge that do not impose a grid on reality, but that emphasize difference. Lyotard's cultural critique is also a critique of scholarly method. He argues that postmodern scholars should not do theory. They are also not to produce new grand narratives of society, but should deconstruct and criticize modernist claims for universalistic knowledge by doing local, microlevel studies that emphasize heterogeneity and plurality (Lyotard 1984a). He rejects the old methodology of social theory, along with any and all of its theoretical claims. This call for a postmodernization of the social sciences and humanities has been echoed by Richard Rorty, Jacques Derrida, and Zygmunt Bauman, and can be seen in the profusion of postmodern case studies and analyses that uncover difference and heterogeneity and celebrate cultural "others."

Postmodern theorists thus range from writers like Jameson and Harvey, who study postmodernity as a historical era, to those like Lyotard and Rorty, who criticize modernist ideology and develop and employ postmodern methodologies for the humanities and social sciences. As a critique of modernist thought, postmodernism is moreover an intellectual orientation that is different from, even if it overlaps with, aesthetic postmodernism, which has emerged in literature, architecture, and the visual arts since the 1960 s and 1970 s as a response to aesthetic modernism. Critics of (academic) postmodernism, which include Habermas and Giddens, criticize both the hypothesized transition from modernity to postmodernity and the intellectual attitude of postmodern scholars. Giddens, for example, claims that in spite of the discontinuities cited by postmodernists, the major institutions of modernity as it existed in the 
nineteenth century and the early twentieth century-industrialism, capitalism, surveillance, and military power-are still in place, and he therefore only wants to go as far as to theorize a late or "radicalized" stage of modernity (Giddens 1990). He and Habermas have both criticized postmodernism's antitheoretical attitude, its epistemological and moral relativism, its irrationalism, and its laissez-faire attitude to politics (Giddens 1990; Habermas 1987). Similar debates exist within postmodern theory, with Harvey (1989) theorizing a transition to postmodernity while criticizing postmodernist thought, and Lyotard (1984b) criticizing Jameson's "totalizing dogmas" and defense of master narratives. ${ }^{6}$

\section{Technology Studies: New Visions of Technology}

\section{Technology Studies as a Field}

"Technology studies" is the name for a loosely knit multidisciplinary field with a wide variety of contributing disciplines, such as sociology, history, cultural studies, anthropology, policy studies, urban studies, and economics. Technology studies are concerned with the empirical study of the development of technical artifacts, systems, and techniques and their relation to society. Technology studies are part of science and technology studies, or STS, a larger field that emerged in the 1970s and that is based on studies of science and technology and their relation to society that are both empirically informed and on sound theoretical footing. STS is today an established discipline, with departments and programs around the world, as well as specialized conferences and journals. $^{7}$

A full review of theories and approaches in technology studies is well beyond the scope of this paper and is complicated because of the relative youth of the field and the diversity of its topics and approaches. In what follows, I focus on two subfields of technology studies that are at the core of many STS departments and programs. They are social studies of technology, which look at social and cultural aspects of technology, and the history of technology, which studies the historical development of technologies and their relation to society. ${ }^{8}$ In discussing the history of technology, moreover, I focus on contextual approaches, which are dominant in STS, and which look at the historical development of 
technologies in relation to their social context, instead of taking an internalist approach that focuses on purely scientific and technological contexts only. ${ }^{9}$ This selective choice means that I ignore, among other studies, the important work that has been done in two distinct fields: economics of technology and philosophy of technology. ${ }^{10}$

Contemporary technology studies, with their focus on social, cultural, and historical dimensions, cover a wide variety of topics. Scholars rarely consider "Technology-with-a-capital-T." Instead, they examine specific technologies, such as genetic engineering or nuclear technology; specific engineering fields and approaches, such as mechanical engineering or cold fusion research; specific techniques, such as rapid prototyping or cerebral angiography; and technical artifacts, machines, materials, and built structures, such as ceramic vases, Van de Graaff generators, polystyrene, and the Eiffel Tower. In addition, many scholars study large technological systems, such as railroad systems or early warning systems in missile defense, and the processes of technological change, such as the development of the bicycle in the nineteenth century or the invention and development of electric lighting.

Technology studies analyze these technological entities in relation to their social context. Roughly, this is done in one of three ways. In one set of studies, the focus is on the shaping of the technology itself and the role of societal processes. How did the technology come into existence? What (social) factors played a role in this process? What modifications has it undergone since it first came into being, and why did these occur? In other studies, the focus is on how a technology has shaped society, or, alternatively, on the social changes that accompanied the introduction and use of the technology. In yet other studies, these processes are considered together, emphasizing how a technology and its social context co-evolve, or co-construct each other. A significant proportion of work that takes up this co-construction theme even denies that there is a meaningful distinction between technology and society, and attempts to study "sociotechnology," which consists of dynamic seamless webs of entities that are only labeled as technological or social after they have fully evolved (Bijker and Law 1992; Latour 1987; Callon 1987). There is also a fourth category of studies in technology, which historian John Staudenmaier (1985: p. 17) calls "externalist," that do not focus on 
technology per se but only on contextual aspects, such as engineer-ing communities, technological support networks, or public images of technology.

The core of contemporary technology studies consists of social studies of technology and the history of technology, both of which have been influenced by New Left critiques of science and technology. I discuss these two subfields in order. In social studies of technology, the research focus is on the social contexts in which technologies are developed and used, such as engineering labs, factories, and homes. The research examines how elements in these contexts interact with each other and with the technology in question. Such elements include individual agents and social groups, along with their behaviors, interactions, identities, and statuses (gender, race, class), as well as organizational structures, institutional settings, and cultural contexts.

Contemporary social studies of technology are in large part an outgrowth of social studies of science. The specific tradition of which it is an outgrowth is sometimes called sociology of scientific knowledge (SSK). The SSK approach to the sociology of science, which is the dominant approach today, holds that scientific knowledge itself, and not just the social and institutional context of scientific inquiry, ought to be the key focus of the sociology of science. SSK holds that scientific knowledge is not a rational process exempt from social influences, but a social process, and that scientific truth is not objectively given but socially constructed. This SSK approach deviates from what was the dominant approach in the sociology of science until the late 1970s: the Mertonian approach, named after Robert K. Merton, which focused only on the institutional context of scientific inquiry while assuming that scientific inquiry itself is by and large rational and objective. SSK also distinguishes itself from traditional (positivist) philosophy of science and epistemology, which also holds scientific inquiry and truth to be rational and objective. Instead, it takes its inspiration from philosopher of science Thomas Kuhn's work on the structure of scientific revolutions, which is critical of images of science as a rational and cumulative process (Kuhn 1962). ${ }^{11}$

It was a founding principle of SSK that "nature" and "rationality" and "truth" in science do not explain the process of scientific inquiry, 
but are themselves contingent social constructs that must be explained. This central principle was extended in the early 1980s, when some SSKers began to publish work in social studies of technology. The principle is modified to read: the working of machines does not provide an explanation of technological and social change, but is itself something that must be explained, at least in part by investigating social agents, their interactions, and their beliefs about technology. ${ }^{12}$ Technology is regarded, in part or wholly, as a social construction that must be explained by reference to social processes, and within which no appeal can be made to objective standards of truth, efficiency or technological rationality.

Although some contemporary work in (contextual) history of technology finds inspiration in social studies of technology, the history of technology is itself a much older field (Cutcliffe and Post 1989; Westrum 1991; Staudenmaier 1985; Fox 1999). Yet, although there has always been an interest in the social context of technology in the history of technology, approaches that put this social context at center stage have only recently come to dominate. A typical study in a contextual history of technology considers how a particular technology, such as electric power transmission, the internal combustion engine, or the personal computer, evolved historically and how the technology came to reflect the contexts in which it has been developed and used. The investigation is often bounded in time (a particular historical era or development stage of the technology) and space (a particular geographical area or setting). Contextual elements that such historians consider may include organizational, policy, and legal settings, including relevant individual actors, social groups, and organizations (engineers, firms, industries, government bodies, activist groups) and their discourses and behaviors. In sociohistorical studies of technology, in which social studies of technology intersect with the history of technology, the development of technologies is studied with special reference to their social contexts and uses (see Bijker 1995b for a review).

Most studies in social studies and the history of technology are case studies that consider particular settings or events in which technologies are developed and used. ${ }^{13}$ Others are what John Staudenmaier (1985: p. 206) calls "expanded studies," which look more broadly at several 
types of technologies or several types of settings or historical episodes. Yet other studies are primarily theoretical or methodological, focusing on such issues as technological determinism or the interpretive flexibility of technological artifacts, or on methodological issues within technology studies. Most studies operate at a micro or mesolevel of analysis, focusing on individual actors, social groups and organizations, and their interactions, rather than on the macrolevel of institutions and cultural frameworks. The research methods are diverse and include textual analysis, discourse analysis, participant observation, ethnomethodology, and quantitative analysis.

\section{Theoretical Claims of Technology Studies}

The strong empirical orientation of most work in social studies and the history of technology is visible, not only in its case analyses, but also in its theoretical and methodological assumptions, which have often been inspired by, or modified as a result of, these case studies. As a consequence of this, there has been a fair amount of agreement on a number of theoretical assumptions. I will try to characterize some of these assumptions, along with some others that are also salient but more controversial.

One of the most central theoretical assumptions in technology studies is the assumption that technology is socially shaped. Technological change is conditioned by social factors, and technological designs and functions are the outcome of social processes rather than of internal standards of scientific-technological rationality; technology is society made durable. ${ }^{14}$ The social shaping thesis denies the technological determinist idea that technological change follows a fixed, linear path, which can be explained by reference to some inner technological "logic," or perhaps through economic laws. Instead, technological change is radically underdetermined by such constraint and involves technological controversies, disagreements, and difficulties that engage different actors or relevant social groups in strategies to shape technology according to their own insights.

Some scholars may discern technological or scientific constraints on technological change, but others point out that such constraints, if they exist at all, are themselves also socially shaped-for example, 
expectations of growth within the business, engineering, or user communities. Also, while some scholars recognize separate stages in the development of technology (e.g., invention, development, innovation), others, particularly in social studies of technology, analyze technological change as an entirely contingent and messy process, in which heterogeneous factors affect technological outcomes, and in which the process of invention continues after technologies leave the laboratory or factory. These scholars emphasize that users, regulators, and others also affect the design and operation of technologies and the way in which technologies are interpreted and used (Bijker 1992; Lie and Sørenson 1996; Oudshoorn and Pinch forthcoming). In contrast to a linear-path model of technological change, proposals have been made for a variation and selection model, according to which technological change is multidirectional: there are always multiple varieties of particular design concepts, of which some die, and others, which have a good fit with social context, survive (e.g., Pinch and Bijker 1987; Ziman 2000).

The social-shaping thesis implies a weak constructivist claim that technological configurations are variable and strongly conditioned by social factors. Social constructivist approaches go beyond this claim to arrive at the strong constructivist claim that technological change can be entirely analyzed as the result of processes of social negotiation and interpretation, and that the properties of technologies are not objective, but are effectively read into the technologies by social groups. Social constructivism is hence a contemporary form of idealism, denying the possibility or desirability of a reference to any "real" structures or forces beyond the representations of social groups. Whether a certain technology works or is efficient or user-friendly, and the nature of its functions, powers, and effects is not a pregiven, but the outcome of social processes or negotiation and interpretation. ${ }^{15}$

Those social-shaping theorists who do not embrace social constructivism also recognize that the meaning or use of technologies is not pregiven. Most theorists agree that technology has interpretive flexibility, meaning that technologies can be interpreted and used in different ways (Pinch and Bijker 1987). When social negotiations surrounding technological change come to a close, interpretive flexibility is held to diminish because the technology stabilizes, along with concomitant (co-produced) 
meanings and social relations. Stabilization implies the embedding of the technology in a stable network consisting of humans and other technologies, and the acceptance of a dominant view on how to interpret and use the technology. Stabilization of a technology implies that its contents are "black-boxed" and are no longer a subject of controversy. Its stabilized properties come to determine the way that the technology functions in society. Yet, black boxes can be reopened. The history of technology shows how technologies such as the telephone, the Internet, or the automobile take on particular functions or societal roles that may vary from time to time and place to place.

The flip side of the claim that technology is socially shaped is the claim that society is technologically shaped, meaning that technologies shape their social contexts. This goes considerably beyond the claim that new technologies may open up new possibilities that change society, or that technologies may have side effects. Obviously, the steam engine changed society by making new types of industrial production possible, and the printing press effected change by making written information more available and easier to distribute. Obviously, also, technologies may have side effects such as environmental pollution or unemployment. The technological-shaping thesis refers not just to such recognized functions and side effects of technologies, but to the multiplicity of functions, meanings, and effects that always, often quite subtly, accompany the use of a technology. Technologies become part of the fabric of society, part of its social structure and culture, transforming it in the process. The idea of society as a network of social relations is false, because society is made up of sociotechnical networks, consisting of arrangements of linked human and nonhuman actors.

The notion of a sociotechnical network is a central notion in actornetwork theory (ANT), which is a third influential approach to technology studies, next to the social-shaping and social-construction approaches. It studies the stabilization processes of technical and scientific objects as these result from the building of actor networks, which are networks of human actors and natural and technical phenomena. Actor-network theorists employ a principle of generalized symmetry, according to which any element (social, natural, or technical) in a heterogeneous network of entities that participate in the stabilization of a technology 
has a similar explanatory role (Callon 1987; Latour 1987; Callon and Latour 1992). Social constructivism is criticized by ANT for giving special preference to social elements, such as social groups and interpretation processes, on which its explanations are based, whereas natural or technical elements, such as natural forces and technical devices, are prohibited from being explanatory elements. Actor-network theory allows technical devices and natural forces to be actors (or "actants") in networks through which technical or scientific objects are stabilized. By an analysis of actor networks, any entity can be shown to be a post hoc construction, but entities are not normally socially constructed because stabilization is not the result of social factors alone.

The notion that society is technologically shaped means, according to most scholars in technology studies, that technology seriously affects social roles and relations; political arrangements; organizational structures; and cultural beliefs, symbols, and experiences. Technology scholars have claimed that technical artifacts sometimes have built-in political consequences (Winner 1980), that they may contain gender biases (Wajcman 1991; Bray 1997), that they may subtly guide the behavior of their users (Sclove 1995; Latour 1992), that they may presuppose certain types of users and may fail to accommodate nonstandard users (Akrich 1992) and that they may modify fundamental cultural categories used in human thought (Turkle 1984, 1995).

Latour (1992), for example, discusses how mundane artifacts, such as seat belts and hotel keys, may direct their users toward certain behaviors. Hotel keys in Europe often have heavy weights attached to compel hotel guests to bring their key to the reception desk upon leaving their room. Winner (1980) argues that nuclear power plants require centralized, hierarchical managerial control for their proper operation. They cannot be safely operated in an egalitarian manner, unlike, for example, solar energy technology. In this way, nuclear plants shape society by requiring a particular mode of social organization for their operation. Sclove (1995) points out that modern sofas with two or three separate seat cushions define distinct personal spaces, and thus work to both respect and perpetuate the emphasis of modern western culture on individuality and privacy, in contrast to, for example, Japanese futon sofa-beds. Finally, Turkle (1984) discusses how computers and computer-operated 
toys affect conceptions of life. Because computer toys are capable of behaviors that inanimate objects are not normally capable of, they lead children to reassess the traditional dividing lines between "alive" and "not alive" and hence to develop a different concept of "alive." Most authors would not want to claim that technologies have inherent power to effect such changes. Rather, it is technologies in use, technologies that are already embedded in a social context and that have been assigned an interpretation, that may generate such consequences.

To conclude, the major insights of technology studies have been that technologies are socially shaped and at the same time society is shaped by technology, or, alternatively, that society and technology co-construct each other. They are not separate structures or forces, but are deeply interwoven. Moreover, technological change is not a linear process but proceeds by variation and selection, and technologies have interpretive flexibility, implying that their meanings and functions and even (according to social constructivists) their contents are continually open to renegotiation by users and others.

\section{Technology Studies and Modernity Theory: Mutual Criticism}

\section{The Treatment of Technology in Modernity Theory}

It is difficult to overlook the pervasive role of technology in the making of modernity. As argued earlier, technology is a central means by which modernity is made possible. It is a catalyst for change and a necessary condition for the functioning of modern institutions. However, it is more than that. What can be learned from technology studies is that the institutions and culture of modernity are not just shaped or influenced by technology, they are also formed by it. The social systems of modernity are sociotechnical systems, with technology an integral part of the workings of social institutions. Social institutions are societal structures that regulate and coordinate behavior and in this way determine how certain societal needs are met. In the modern age, however, their regulative functions are no longer a direct outcome of collective actions, since most collective actions have become thoroughly mediated and shaped by modern technologies, which function as co-actors. For example, collective acts of voting are now thoroughly mediated by voting technologies 
that help determine whether people get to vote at all, how votes are defined, and whether votes are counted. Modern culture is, likewise, a technological culture, in which technologies are not just material substrates of existing cultural patterns, but also have a major role in defining, shaping, and transforming cultural forms. Information technology, for example, is transforming basic cultural concepts and experiences such as those of time, space, reality, privacy, and community and is also effecting fundamental shifts in cultural practices.

If this analysis of the role of technology in modernity is anywhere near correct, then it is surprising, to say the least, to find that technology is not a central topic in the vast literature in modernity theory. Indeed, of the many hundreds of books that bear the word "modernity" in the title, fewer than a handful also refer to technology or one of its major synonyms or metonyms (e.g., technological, computers, biotechnology, industrial). ${ }^{16}$ Many of the major works in modernity theory make only passing reference to technology. For example, technology is referenced only once in the recent edited volume, Theories of Modernity and Postmodernity; it is not mentioned at all in Zygmunt Bauman's Intimations of Postmodernity; and there are only four or five brief references to it in Alain Touraine's Critique of Modernity (see Turner 1990; Bauman 1992; Touraine 1995).

What can explain this apparent neglect of technology in modernity theory? It is not denial that technology has an important role in the constitution of modernity, for most authors would agree that its role is pivotal. A better explanation is that the dominant dimensions along which modernity has traditionally been analyzed (institutional, cultural, and epistemological) have not allowed technology to play a major identifiable role, but have instead assigned it the status of a background condition. Technology is often analyzed as a mere catalyst of institutional, cultural, and epistemological change, or as a mere means through which institutions, cultural forms, and knowledge structures are realized.

In institutional analyses, modernity is analyzed as being constituted by institutions and their transformations. Technology is not usually recognized as an institution itself; it is not seen as a separate regulative framework such as capitalism, government, or the family, but rather as one of the means through which these frameworks operate. More often 
than not, institutions such as capitalism, industrialism, or military power are discussed without specific reference to the technologies that sustain them. The role of technology in transforming these institutions (e.g., in the transition to an information society) is more difficult to ignore. However, here one often finds technology subsumed as part of a broader phenomenon, such as rationalization (Weber), productive forces (Marx), or disembedding mechanisms (Giddens), of which it is only a part. Even in Marxist theory, which assigns an important role to production technology in the making of modernity, this technology still only serves as an external constraint on economic structure, which ultimately determines the social forms of society.

In most cultural and epistemological theories of modernity, technology is either analyzed as a mere catalyst of cultural and epistemological changes, or it is robbed of its materiality and reduced to knowledge, language, or ideas. In Heidegger's critique of modernity, in which technology "enframes" us and turns the world into "standing reserves," technology turns out not to be defined as a material process or as a mode of action, but as a particular mode of thinking (Heidegger 1977). The same idealism is also visible in much of critical theory, in spite of its greater emphasis on social institutions. There, technology is often identified with technological or formal rationality, which is a mode of thinking that characterizes not only modern technology but also modern thought and economic and social processes. Habermas, moreover, has defined technology as "technological knowledge and ideas about technology" (Habermas 1987: p. 228). Finally, in postmodern theory, technology is often reduced to language, signs, or modes of knowledge, along with everything else.

When technology is referred to in modernity theory without being reduced to something else, still other problems emerge. One is the level of abstraction at which technology is discussed: technology is usually treated as a monolith, as a macroscopic entity, Technology-with-acapital-T, about which broad generalizations are made that are supposed to apply equally to nuclear technology and dental technology, to vacuum cleaners and gene splicers. This abstract, undifferentiated treatment leads to vagueness, obscures differences between technologies, and fails to distinguish the varied ingredients that make up technology 
(knowledge, artifacts, systems, actions) and the way these relate to their context.

Giddens, for example, employs the notion of an "expert system," which is a key mechanism for decontextualizing social relations. He defines expert systems as "systems of technical accomplishment or professional expertise that organize large areas of the material and social environments in which we live today" (Giddens 1990: p. 27). He discusses few examples of expert systems, but makes it clear that virtually any system in which the knowledge of experts is integrated and that contains relevant safety measures qualifies as an expert system, including automobiles, intersections, buildings, and railroad systems. Moreover, Giddens goes into hardly any detail on the way in which expert systems decontextualize social relations.

A monolithic treatment of technology easily leads to essentialism and reification. In an essentialist conception, technology has fixed, contextindependent properties that apply to all technologies. As Andrew Feenberg (1999a: pp. viii-ix) has argued, technological essentialism usually construes technology's essence as its instrumental rationality and its functionalism, which reduces everything to functions and raw materials. This essentialism often correlates with a reified conception of technology, according to which it is a "thing," with static properties, that interacts with other "things," such as the economy and the state. Essentialism and reification, in turn, have a tendency to promote technological determinism, in which technology develops according to an internal logic, uninfluenced by social factors, and operates as an autonomous force in society, generating social consequences that are unavoidable. ${ }^{17}$ Technological determinism is evident in dystopian critiques of modernity, such as those of Heidegger, Marcuse, and Ellul, in which technology engulfs humanity and rationalizes society and culture. In many other theories of modernity, it is also present, albeit in a more subtle way. Marx's thesis that the productive forces determine or constrain production relations has often been interpreted as a form of technological determinism. Daniel Bell (1976) presents a similar view in characterizing the transition to a postindustrial society as the result of economic changes that are due to increased productivity, which is conditioned by information technology. Baudrillard (1995) construes the transition from modernity 
to postmodernity in technological determinist terms by analyzing it as the result of information technology and media, whose models and codes yield a new social order. James Beniger's (1989) detailed historical study of the making of the information society is also built on technological determinist principles, with technological change being a cause of social change, while itself remaining relatively independent of social influences.

In conclusion, the treatment of technology in modernity theory is problematic in several respects. Often, technology is not assigned a major role in modernity; it is subsumed under broader or narrower phenomena or one-dimensional phenomena; its treatment is often abstract, leading to vagueness, overgeneralization, detachment from context, and a failure to discern detailed mechanisms of change. In addition, technology is often reified and essentialized, and the conceptions of it are often deterministic. There is also the problem that modernity theory's sweeping generalizations about technologies do not normally rest on microlevel elaborations of the macro theory or on case studies. Modernity theory's generalizations, it will be clear by now, tend to go against many key ideas of technology studies (the social character of technology and its interpretive flexibility, the path dependence of technological change, etc.). Moreover, when theories of modernity provide inadequate accounts of technology and its role in modernity, their accounts of social institutions, culture, and the dynamics of modernity suffer as well. There are theories that avoid many of the problems listed (e.g., Castells 1996), but they are exceptions to the rule.

\section{The Treatment of Modernity in Technology Studies}

Modernity theory must provide an account of technology because of its major role in the shaping of modernity. Technology studies, on the contrary, do not seem to require a consideration of modernity in their analyses of technology. It is not obvious that a historical study of the telephone or an analysis of the development and advertisement of fluorescent lighting must refer to macroscopic structures and events such as disembedding mechanisms and changes in capitalist production modes. And in fact, most work in technology studies does not refer to such macro structures but instead remains at the micro (or meso) level. It 
studies actors (individuals, social groups, organizational units); their values, beliefs, and interests; their relations and (inter)actions; and the way in which these shape or are shaped by specific technologies. Case studies and extended studies based on this approach contain rich descriptions of complex dynamics that lead to social and technological outcomes. However, the aim of many of these studies is not just to describe what happens, but also to explain why it happened. For example, in analyzing the history of the Penny Farthing bicycle, Pinch and Bijker (1987: p. 24) do not want to only describe various bicycle models and the social groups involved in their manufacture and use; they want to understand the factors that determine what models are successful and the reasons social groups assign certain meanings to a model. I argue that microlevel accounts cannot fully explain technological and social change unless they are linked with macrolevel accounts.

The main reason for this is that a sufficiently rich account of actors and their relationships, beliefs, and behaviors requires an analysis of the wider sociocultural and economic context in which these actors are operating. This broader analysis is needed to explain why actors have certain attitudes, values, beliefs, or relationships, and it may even be necessary to infer their very existence. For example, an understanding of why certain types of men were attracted to high-wheeled bicycles in late nineteenth-century England, and perhaps also the identification of social groups with this attraction, is likely to require an account of masculine culture in late nineteenth-century England. The failure to look at this cultural context would result in superficial and possibly also unreliable descriptions of actors. More generally, to base explanations of technological and social change merely on observations of actors and their behaviors would be to subscribe to a form of methodological individualism, a questionable form of reductionism that holds that social explanations can be reduced to facts about individuals and hence that no reference to supraindividual social structures is required (Lukes 1994).

Granted, the actors in technology studies also include more complex entities, such as social groups and organizations, and nonhuman actors such as machines, but these are still particular actors to which agency is attributed, frequently along with beliefs and attitudes. If the actions, 
beliefs, and attitudes of these actors are not related to wider sociocultural contexts, then any explanation is likely to fall short. This is a recurring problem in most approaches in technology studies that emphasize an actor perspective, including social-shaping and social-constructivist approaches and the actor-network approach of Bruno Latour, Michel Callon, John Law, and their associates. This latter approach does relate the properties of individual actors to a wider context, which is the network of actors in which they are operating, and holds that this network defines these properties. However, the networks are limited in scope, usually containing only the actors thought to have a direct role in the development or functioning of a particular technology. Actor-network studies rarely provide sufficiently complete accounts of the networks that shape the behaviors or attitudes of the other actors in the network (e.g., engineers, corporations, or politicians), who therefore tend to be analyzed in a methodological individualist way. ${ }^{18}$

There is also another reason microlevel approaches have only limited explanatory power. As Paul Edwards points out (chapter 7, this volume), a major distinguishing feature of modern societies is their reliance on infrastructures, large sociotechnical systems such as information and communications networks, energy infrastructures, and banking and finance institutions. As Edwards argues, these infrastructures mediate among the actors that are studied in microlevel analysis. In this sense they function as disembedding mechanisms, defining social relations and guiding social interactions over large distances of time and space (Brey 1998). However, these infrastructures themselves are best studied at the macrolevel. Microlevel approaches that ignore infrastructures run the risk of providing an insufficient account of the relations between actors in modernity (whereas accounts of social relations in premodern societies can more easily remain at the microlevel because they are not usually mediated by infrastructures). The recent transition to a post-Fordist, global economy has heightened the inadequacy of microlevel analyses by fragmenting industrial production and marketing and reorganizing it on a global scale (Rosen 1993).

Social constructivists, while acknowledging the need to consider the societal context in which actors operate, have sometimes objected to an appeal to social theory because of its "realism," which would be 
incompatible with (strong) social constructivism (see, e.g., Pickering 1995; Elam 1994) However, there is no inconsistency in invoking categories of social theory in social constructivist analyses. Social constructivist explanations proceed by deconstructing entities in terms of the activity of other entities, specifically social groups. These entities are often not deconstructed themselves for pragmatic reasons because deconstruction has to stop somewhere. For instance, Bijker's (1992) social constructivist analysis of fluorescent lamps refers to the involvement of General Electric as a "real” entity. As Bijker (1993) later explained, his primary interest had been the social construction of fluorescent lamps, and not the social construction of General Electric. Because of this specific interest, it was excusable to present some parts of the sociotechnical world as fixed and as undeconstructed entities that function in the explanation of the development of fluorescent lamps, even though these entities are social constructions as well. But if reference can be made to General Electric in social explanation, then surely reference can be make to Fordism, disembedding mechanisms, and other socially constructed entities of social theory. ${ }^{19}$

Another criticism of modernity theories, and a reason cited for avoiding them, is their alleged tendency to totalization, universalization, functionalism, rationalism, panopticism, and determinism, not just in their treatment of technology, but in their treatment of society as a whole. This mirrors the criticism by postmodernists of macrolevel metanarratives. Tom Misa has argued, for instance, that macrolevel theories tend to "impute rationality on actors' behalfs or posit functionality for their actions, and to be order-driven," and that these tendencies quickly lead to "technological, economic or ecological determinism." Microlevel studies, instead, focus on "historical contingency and variety of experience" and are "disorder-respecting" (Misa 1994: p. 119). While the former tendencies are clearly visible in the majority of theories of modernity, I hold that they are not inherent to macrotheorizing. The macrostructures postulated in macrotheories inevitably impose constraints on the actions of individuals, but this does not mean that they must also determine these actions. Moreover, macrostructures can be defined as contingent, heterogeneous, and context dependent, such as Castells' networks. 
A final objection to macrotheories is that they are often speculative and not elaborated or tested empirically. While there are good exceptions (again, Castells), these virtuoso performances confirm the general rule. My point is that this category of theorizing should not be rejected, but instead that these theories should be developed, tested, and refined. I conclude, tentatively, that there are no good reasons for scholars in technology studies to avoid macrotheories of modernity and that there are good reasons to employ them. Working toward integrated studies of modernity and technology involves, then, developing and testing macrotheories and working to bridge the micro-macro gap that now often separates modernity theory from technology studies. These two tasks are the topic of the next section.

\section{Modernity, Technology, and Micro-Macro Linkages}

\section{The Problem of Micro and Macro}

In large part, the problem of connecting the topics of modernity and technology, and of connecting modernity theory with technology studies, is the problem of connecting the macro with the micro. Modernity theory typically employs a macrolevel of analysis, analyzing macrolevel phenomena, such as late modernity and globalization, in terms of other macrolevel phenomena, such as time-space disembedding and the gradual decline in Western global hegemony. Much work in technology studies operates at the micro level, analyzing microlevel entities such as fluorescent lighting or the advertising of a new daylight fluorescent lamp by reference to other microlevel entities such as "the influence of Ward Harrison of the incandescent lamp department of General Electric" or "the writing of a report on daylight lighting by the Electrical Testing Committees." In addition, one could claim that modernity theory typically employs a structure perspective, focusing on social structures and their properties, whereas technology studies often employ an actor perspective.

I assume that there is a mutual need in technology studies and modernity theory to bridge the gap between the micro and the macro, and between structure and actor perspectives. Nevertheless, the problem of micro and macro (not to mention the problem of structure and agency) 
remains one of the great unsolved problems in social science. In spite of the attention this problem has generated, there is still no recipe, no method, and few inspiring exemplars on how to connect macrolevel and microlevel analyses. In the discussion that follows, I try to advance this general issue by looking more analytically at the problem. I argue that progress on the micro-macro problem has been hampered by a failure to recognize the multiplicity of levels of analysis (micro and macro being coarse distinctions only) and a failure to distinguish two distinct dimensions within the micro-macro distinction: size and level of abstraction. I then outline four principal ways in which levels of analysis may map onto each other, and conclude by drawing implications for an integration of modernity theory with technology studies.

\section{Size and Level of Abstraction}

What makes a phenomenon studied in the social sciences or humanities a macro phenomenon? And what makes a concept a microlevel concept? Considerable confusion exists over this matter. Sometimes it is held that macroanalysis is distinct from microanalysis because it focuses on larger things. Social systems are large and individuals and their actions are small; therefore social systems are the subject of macroanalysis and individuals the subject of microanalysis. Another claim sometimes made about the micro-macro distinction is that macrolevel phenomena and the concepts that refer to them are abstract and general, whereas microlevel phenomena tend to be concrete and specific.

Thus there are at least two parameters along which macroanalyses are distinguished from microanalyses: the size of the units of analysis, and their level of abstraction. ${ }^{20}$ Very few attempts exist in the literature to further define or operationalize these parameters, or to study their interrelationships. It is usually assumed that they tend to interrelate; that the units of macrolevel analysis are typically, if not invariably, large, abstract, and general, whereas things in microlevel analysis tend to be small, concrete, and specific. Yet there are many exceptions to this rule. For example, the modern self is both smaller and more abstract than protest marches during the inauguration of George W. Bush. The modern self is a smaller unit of analysis because protest marches involve many modern selves. It is more abstract because it refers to a general 
type of phenomenon, whereas the protest marches denote a specific type of phenomenon. Other units of analysis do not seem to have a definite size at all. For example, reflexivity is a property that can apply to both large things (e.g., social systems) and small things (e.g., the knowledge processes of organizational units).

To understand the connections between the micro and the macro, we must therefore first better understand the parameters by which these notions are defined-the notions of level of abstraction and size. I discuss these in order.

Level of Abstraction What does it mean to say that one phenomenon is more abstract than another? Principally, I want to argue, this means that the phenomenon is more general. For example, rationalization is a more general process than the standardization of testing in aviation schools (a form of rationalization), and that is why it is more abstract. Starting from an abstract phenomenon, one can arrive at more concrete phenomena by introducing additional properties that bound it. Starting with the abstract phenomenon of industrial society, one can arrive at the more specific and therefore more concrete phenomenon of late nineteenth-century British industrial society by adding properties that specify time period and nationality. Likewise, starting from the notion of a parent, one can arrive at the somewhat more concrete notion of a mother (a female parent) by adding a gender property (female). Conversely, when one starts with a concrete phenomenon, one can arrive at a more abstract one by removing properties from it. One can go from late nineteenth-century British industrial society to industrial society and from mother to parent by subtracting properties, that is, by generalizing.

In this way it is possible to construct hierarchies of entities that range from abstract to concrete, with the more concrete entities being species (subtypes or instances) of the more abstract entities. For example, one can construct a hierarchy going from transportation vehicle to bicycle to Penny Farthing bicycle to the Bayliss-Thomson Ordinary Penny Farthing bicycle to the specific Bayliss-Thomson Ordinary Penny Farthing bicycle of which I have a picture. Notice, however, that concretization is not just a matter of adding adjectives (or abstraction a matter of subtracting them). The relation between more abstract and more concrete 
phenomena is not always linguistically transparent, and conceptual analysis, if not empirical investigation, may be needed to observe the relation (e.g., that a mother is a type of parent, or that a standard-setting body in health care is a type of bureaucratic organization).

Size Units of analysis can often be ordered according to their size. For example, a social system is obviously larger than a social group in that system, and a social group is larger than an individual in that group. The reference to size here does not imply a reference to absolute metric or numerical properties. Rather, size is used here in a relative or comparative sense. Phenomenon $a$ is larger than phenomenon $b$ if $a$ can contain $b$, or $b$ is a part of $a$. For example, there are part-whole relations between the economy and the individuals participating in it because an analysis of economic processes ultimately reveals individuals engaged in economic behavior. This is why economic systems are larger than individuals. Large units of analysis are larger than small units of analysis because they are able to stand in a part-whole relation or a relation of (partial) containment to these smaller units (Castells 1996: pp. 174-179). Because parts may have parts themselves, hierarchies can be constructed of units of analysis that range from large to small. For example, a social system may include a market system that includes organizations that include organizational units that include divisions that include employees. Likewise, the British railway system includes train stations that include platforms and station staff. Also, items may be parts of multiple wholes. For example, pay-per-view virtual museums may be part of the post-Fordist economy, but they are also part of postmodern culture. Notice that part-whole relations between units of analysis, which refer to their size, are clearly different from the types of genus-species relations discussed earlier, which refer to level of abstraction. For instance, Internet advertising is a species of advertising, but a part of the post-Fordist economy.

\section{Levels of Analysis and Their Interrelationships}

What the distinction between size and level of abstraction shows is that the micro-macro distinction encompasses at least two hierarchies: a hierarchy from abstract to concrete and one from large to small. Things can be simultaneously small and abstract (the modern self) or large and 
concrete (the locations of capital cities across the globe in the year 2001). In practice, however, there are correlations between these two hierarchies. What should also be clear from the discussion is that the distinction between two levels of analysis (macro and micro) or even three levels (macro, meso, and micro) is a gross oversimplification. Going from abstract to concrete or from large to small, many levels may be encountered in between. So what is commonly called the "macrolevel" in fact relates to multiple levels of analysis that may range from very large or abstract phenomena such as modernity, western culture, and industrial society to significantly smaller or more concrete entities such as the Internet economy, gender in late nineteenth-century France, and the Kansai region in Japan. Similarly, microlevel phenomena may range from larger and more abstract entities such as advertising agencies, hackers and local area networks, to smaller or more concrete entities such as Bill Gates, Mary's filing of a petition, and the software error in Fred's computer.

The terminology of micro and macro is therefore too coarse because it does not distinguish between size and level of abstraction, and it does not discriminate the different levels and hierarchies that exist within macro- and microlevel analyses. The consequence of this is that it becomes difficult to see how various kinds of micro- and macrolevel analyses may be integrated with each other. Yet, arriving at an adequate integration of levels of analysis is the major problem faced by theories of modernity and technology. How do you get from a discussion of late modernity, rationalization, and the state to a consideration of the development and use of specific technologies? Conversely, how do you get from talk about Pentium computers, hacker culture, and virtual communities to talk about globalization, the modern self, and post-Fordist economies? Any adequate study of modernity and technology requires such a bridging of the micro and the macro, of the abstract and general and the concrete and empirical, of the large and diffuse and the small and singular.

The major question, then, for theories of modernity and technology, is how the gaps that exist between different levels of analysis can be bridged. My distinction between size and level of abstraction indicates that gaps between levels occur in two ways: because the higher level 
refers to more abstract phenomena than the lower level (e.g., bureaucratic organizations versus standard-setting bodies in health care), or because it refers to larger phenomena (e.g., social systems versus markets). But my discussion also suggests how these gaps may be bridged: by identifying genus-species relationships (for phenomena at different levels of abstraction) and part-whole relationships (for phenomena of different sizes). For instance, an analysis of standard-setting bodies in health care may be linked to an analysis of bureaucratic organizations by identifying standard-setting bodies as species or instances of bureaucratic organizations. Similarly, an analysis of markets may be linked to an analysis of social systems by identifying markets as subunits within social systems. Such matches provide the conceptual links that are necessary to connect discourses that would otherwise remain disconnected.

However, in most studies in the social sciences and humanities that involve the linking of levels of analysis, the aim of such linking is not merely to connect disparate discourses. Most studies have a more specific aim; for instance, explaining events at the micro level, or analyzing the structure of macrolevel phenomena. Most studies center on a specific macro- or microlevel phenomenon that the study aims to analyze (e.g., late industrial society, or changes in the design of the bicycle in the late twentieth century). Links created to levels of analyses that are either higher or lower than that of the analysandum are hence asymmetrical: the higher- or lower-level entities are invoked to explain or analyze the analysandum.

\section{Four Types of Interlevel Analysis}

When something is analyzed in terms of phenomena at another level, these phenomena may be from a lower or a higher level, and may differ in their level of abstraction and their size. This implies that there are four ways in which analysis may bridge levels. I call these "decomposition" (the analysis of a larger unit in terms of smaller units), "subsumption" (the analysis of a smaller unit by reference to larger units), "deduction" (the analysis of a more concrete unit by analyzing it as a subclass of a more general phenomenon) and "specification" (concretization; analyzing a more abstract unit by analyzing one or more of its more concrete forms). I discuss these in order. 
- In decompositional analysis (or reductive analysis), a large phenomenon is analyzed in terms of (much) smaller phenomena. For example, the behavior of markets (at the macro level) is analyzed as the product of the behavior of individuals (at the micro level).

- Subsumptive analysis is the opposite of decompositional analysis. With it, one tries to account for smaller phenomena by (partially) subsuming them under a larger (structural, functional, or causal) pattern of which they are a part. For example, given the macroevent of a transition from Fordism to post-Fordism, in which the bicycle firm Raleigh (a microentity) is one of the players, there is a modest expectation that Raleigh will invest in product differentiation, since product differentiation is part of the transition to post-Fordism (see Rosen 1993).

- In deductive analysis, a phenomenon is identified as a species or token of a more general phenomenon, and knowledge about this more general phenomenon is subsequently applied to the more specific phenomenon. That is, one deduces features from the general to the specific. For example, a regulatory agency in health care is identified as a bureaucratic organization, and one's theory of bureaucratic organizations is subsequently applied to it.

- In specificatory analysis, finally, a phenomenon is studied by identifying and studying one or more subtypes or tokens of it. Case analysis, when used to elaborate a more abstract analysis, is one type of specificatory analysis, one that makes reference to tokens. An example of specificatory analysis is Castells' analysis of East Asian business networks (a meso unit). Castells analyzes them by distinguishing various kinds (at meso- and microlevels of analysis) and studying their similarities and differences (Castells 1996: pp. 174-179).

\section{Implications for Studies of Technology and Modernity}

This perspective on levels of analysis can be used to show how modernity theory can incorporate lower-level analyses in technology studies and how technology studies can make better use of higher-level analyses in modernity theory. To begin with the former, macrolevel modernity theory can benefit from microlevel work in technology studies by using such work to elaborate its macrolevel descriptions in a way that makes 
the overall account more concrete and empirical. Such elaboration can proceed through a process of decomposition and specification in which macro units are decomposed into smaller parts and concretized through the identification of species or subtypes. For example, in an elaboration of the notion of the bureaucratic organization, decomposition would specify the components of bureaucratic organizations, and specification would aim to distinguish various sorts of bureaucratic organizations. Both types of analysis may be repeated to arrive at levels of analysis that refer to ever smaller and more concrete phenomena. Such elaboration makes macrotheories both more easily testable and more capable of informing microlevel analyses. Such elaboration ultimately makes it easy to link up with the lower-level analyses of technology studies.

The incorporation of modernity theory into studies of technology can be similarly clarified. Here, the required types of analysis are subsumption and deduction. To illustrate, Paul Rosen (1993) has attempted to use David Harvey's theory of the shift from a Fordist mode of production to flexible accumulation in the late 1960s and early 1970s in an explanation of the constant shifts in the design of mountain bikes. Connecting this latter fact to Harvey's theory requires deduction (e.g., identifying it as a species of product differentiation, a process mentioned in Harvey's theory) and subsumption (e.g., identifying accompanying advertisements as part of the dialectic of fashion and function in post-Fordist economies). To make an adequate connection, Rosen has to do a good deal of level building, analyzing the cycle industry and advertising at various levels. This not only involves bottom-up construction (building up levels from his microlevel analyses of mountain bike design, firms, and advertisements) but also top-down construction (elaborating Harvey's theory). This makes it possible for him to have the two analyses meet halfway.

I conclude that integrated analyses of technology and modernity, which build on macrotheories of modernity and microtheories of technology, are possible, although they require hard work. Analysts have to work at level building, engaging often in decomposition, subsumption, deduction, and specification. This, I believe, is the responsibility of both modernity theorists and scholars in technology studies. It is a joint project that can begin to abolish the boundaries between two now all-tooseparate fields. 


\section{Notes}

1. For some recent attempts in technology studies to appropriate (and update) existing theories of modernity, see Feenberg (1995, 1999a), Rosen (1993), and Slevin (2000). For attempts at a theory of modernity from within technology studies, see Latour (1993) and Law (1994).

2. For further discussion of the notions of modernity, modernism, and modernization see Featherstone (1991), Turner (1990), and Harvey (1989).

3 . What is and is not a defining aspect of modernity is, of course, a matter of debate. Thus, whereas some would consider gender to be just a social form within modernity, others have argued that it a major constitutive force, and that our very conceptions of the modern are the result of a deeply gendered ontology (e.g., Felski 1995; Marshall, chapter 4, this volume).

4. For an account of Marx's theory of modernity, see Antonio (2001). For Weber, see Scaff (1989) and Turner (1993). Sayer (1991) and Giddens (1973) treat Marx's and Weber's accounts jointly.

5. Compare Lyotard and Thébaud (1985: p. 9): "Postmodern is not to be taken in a periodizing sense." At other times, Lyotard seems to endorse an epochal conception of postmodernity in which postmodernity is the cultural condition that has resulted from the information technology revolution (cf. Lyotard 1984: p. 3).

6. For reviews of postmodern theory, see Best and Kellner (1991) and Smart (2000).

7. For surveys of STS as an academic field, see Jasanoff et al. (1995), Cutcliffe and Mitcham (2001), and Cutcliffe (2000).

8. See MacKenzie and Wajcman (1999) for a representative anthology of social studies of technology, and see its introduction for a survey. See Fox (1999) for a review of themes and approaches in the history of technology.

9. See Staudenmaier (1985) for a review of the contextual approach and its history. 10. See the respective reviews by Dosi et al. (1988) and Mitcham (1994). Achterhuis (2001) surveys contemporary American philosophy of technology.

11. Bloor (1976) is a seminal work in SSK. Other important works include those by Latour and Woolgar $(1979,1986)$ and Latour (1987).

12. See Woolgar $(1991,1996)$ and Bijker (1993) for accounts of the turn to technology in social studies of science. The early classic that marked the beginning of contemporary social studies of technology is still Pinch and Bijker (1987).

13. Staudenmaier (1985: p. 201) has surveyed this for the history of technology. My own review of issues from the year 2000 of the journals Social Studies of Science and Science, Technology and Human Values confirms that the same is true for social studies of technology.

14. For one of the original statements of this position, see MacKenzie and Wajcman (1985). 
15. Pinch and Bijker (1987) give a classical statement of social constructivism in technology studies, specifically of the influential social construction of technology (SCOT) approach. For a recent review of social constructivist approaches, see Pinch (1999).

16. Based on a search on title words at Amazon.com, January 2001.

17. See Smith and Marx (1994) for a historical and Winner (1977) for a philosophical critique of technological determinism.

18. For critiques of the lack of attention of (constructivist) technology studies to sociocultural contexts, see Rosen (1993) and Winner (1993).

19. Along the same lines, the rejection by actor-network theory of social theory because it maintains artificial distinctions between society, nature, and technology is also overstated because these distinctions are not evident in many concepts in social theory. Such notions as disembedding mechanisms (Giddens), rationalization (Weber), and the Net (Castells) are all defined as sociotechnical phenomena.

20. Time scale is an often-mentioned third parameter (see Edwards, chapter 7 in this volume). It is often claimed that macro-analysis typically analyzes processes stretching over years or even centuries, whereas micro-analysis covers shorter time spans, ranging from minutes to months.

21. My claim that large units of analysis may have smaller units of analysis as parts does not imply the reductionist claim that larger units of analysis are wholly composed of smaller units of analysis and therefore can be analyzed without remainder in terms of these smaller units and their relation to one another. I am skeptical about this. 